\title{
The effects of transportation system on the urban sprawl process for the city of Iasi, Romania
}

\author{
C. Iațu, A. Munteanu, M. Boghinciuc, R. Cernescu \& B. Ibănescu \\ Department of Geography, Alexandru Ioan Cuza University of Iasi, \\ Romania
}

\begin{abstract}
The exaggerations of housing blocks during the Romanian communist regime were maintained by the growth of income for the middle class population. After 1989 , this situation led to the movement of part of the urban population towards the outskirts of the city, a process doubled by the chaotic construction of individual houses. Larger distances between residential areas and work or educational places were the main causes of an increasing individual mobility. In this case, the city of Iasi suffers an unprecedented urban sprawl which took the form of periurbanisation. This paper presents one of its negative sides consisting in the growing demand of individual transport, but also its retroaction, the way in which the increasing car ownership fuels the urban sprawl. This interdependency has been outlined first by analysing the growth of private car ownership, and also the increase of cars among households and by evaluating the efficiency of public transportation in the periurban area. In a second plan, the transport input in the urban sprawl is marked by the evolution of the built-up areas and by the changes produced in land use. The survey revealed a subordination of the public transport to personal car travel in the periurban area, a relationship translated by a smaller frequency of transportation and by a more reduced flow of passengers compared to the city. The use of some of the good farmland has been changed, ignoring the risk of geomorphological destabilization due to the dissolution of old vineyards which sustained the slopes. The construction pace surpasses the means of local administration to ensure the city services or to control the traffic and the architectural changes. Environmental problems are also an issue due to the periurbanisation and the growing individual transportation. The spatial effects of Iasi urban sprawl are valid to all large Romanian cities.
\end{abstract}


Keywords: post-communism, urban sprawl, periurbanisation, urban transport, land use, urban-rural dynamic, car ownership.

\section{Introduction}

Urban sprawl is one of the phenomena which require more attention from urban planners and from the related specialists because of its rapidly growing scale and also because its effects are not always desirable. This spatial process brings up a complex issue, involving demographic, economic, environmental and decisional factors and can take different forms, depending on the specifics of the area. The transport appears to be one of the main factors that should be considered, since the distance between the functional urban areas is rapidly increasing and the local authorities have difficulties keeping pace with the rhythm of urban expansion in order to ensure a sustainable development of the networks and to reduce its adverse impact on the environment and the society (Liu et al. [1]).

The aim of this paper is to identify the relation between the evolution of the transport system and the specificity of the urban sprawl of the city of Iasi, Romania, emphasizing the role of the car ownership in the process.

The methodology used consists of the analysis of statistical data for the time frame 1998-2009 concerning the city of Iasi and ten of the surrounding rural communes, which are part of its Metropolitan Area. The data were related to demography (population number, migration balance), number of dwellings, living area and car ownership. The transport system has been analysed according to the evolution of the lines towards the rural areas, the traffic frequency and passenger flows, based on our observations, as well as on the data supplied by the Local Public Transport Company of Iasi Municipality. We have also analysed the land cover balance of this territory according to CORINE Land Cover (CLC) 2000 and 2006 in order to assess the changes that had occurred in land use during this period of time. Correlations have been made between the different indicators as a mean to establish the role of the car and the public transport in the urban extension towards the neighbouring communes.

\section{The context of urban development in Romania}

During the communist decades, the territorial extension and/or retrenchment of the large cities were brutal and, sometimes, it was made without the preexistence of the infrastructure. The massive industrialization carried on by the communist regime (more obvious after 1965) has brought the young rural population in new and large urban residential buildings which were not built necessarily for their comfort (the housing was small, instable and even insalubrious). In 1974, the law for the systematization of the territory gave a more restrictive framework for the built-up areas. The rural settlements were the most affected by this law given the existence of building restrictions outside the perimeter, now legally established. Inside the large cities, the new districts were built either towards villages situated in the proximity of the city or they appeared after a metamorphosis of the pre-existent districts. 
The fall of the communist regime in 1989 marked the beginning of a series of radical changes across the Romanian territory. The massive deindustrialization, the under-use of the surplus labour force and the reconversion of urban spaces were the main processes that redefined the Romanian urban areas. The beginning of the 90's marks also a reversing demographic flow once the second stage of periurbanization of the Romanian territory. This time, part of the urban population establishes residence on the outskirts of the city. This new phase of the phenomenon has been nourished by economic and social chocks which were a rule of the progress towards a healthy capitalist economy but also by a desire to better individualise the private property by leaving the collective communist dwellings and by running away from urban stress. This periurban mutation has been also a mean to spend money and to show off the recently acquired fortune.

The industrial restructuration between 1990 and 2006 has been accompanied also by a social crisis provoked by a significant growth of the unemployment rate in the large industrial centres and in small mono-industrial centres. The unemployment and the restitution of agricultural properties after 1991 lead to a relative agrarisation of the Romanian economy, process accentuated also by an urban-rural migration.

As it is obvious, the excessive concentration of population in a specific hierarchical level always leads towards a decongestion tendency, either by a diffusion of the periurban process in the rural space, or by an expansion of urban centres situated in the proximity levels.

\section{The emerging urban demographic and housing patterns of Iasi}

The municipality of Iasi, Romania's second demographic centre according to the statistical data available for July $1^{\text {st }} 2009$, is situated in the Romanian North-East Development Region (figure 1).

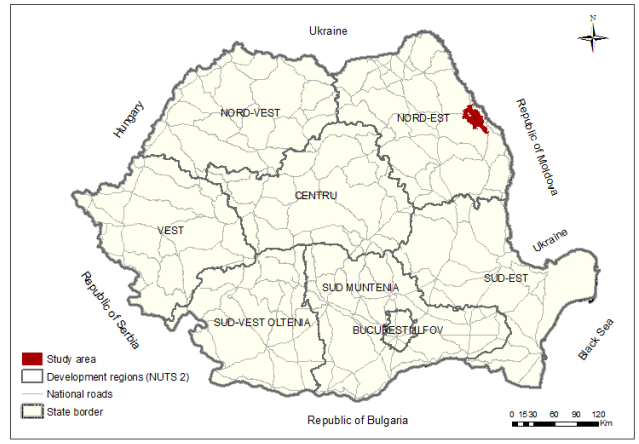

Figure 1: The territorial localisation of the study area (Iasi municipality and its. periurban area). 
It is a city that follows the same trend of urban evolution as the entire Romanian urban system. In order to identify the emerging demographic and housing patterns, we have employed a correlation between the dynamic of population and of the living area for the city and the ten neighbouring rural communes by mapping the results. The second figure shows a close connection between the two indicators in most of the cases. First of all, it is obvious that the city is the only one with a negative dynamic of the population, as well as a very low increase of the living area. One of the reasons could be the fact that there is not too much available land left inside the city. The high density typical to the urban areas becomes unattractive to those who want to build a house. They eventually prefer a greener or less stressful landscape and that explains the growth rhythm of rural areas such as Barnova, Aroneanu or Miroslava. For instance, Miroslava and Barnova reach the highest values for both indicators, succeeding in having a population growth and also a high value of the living area.

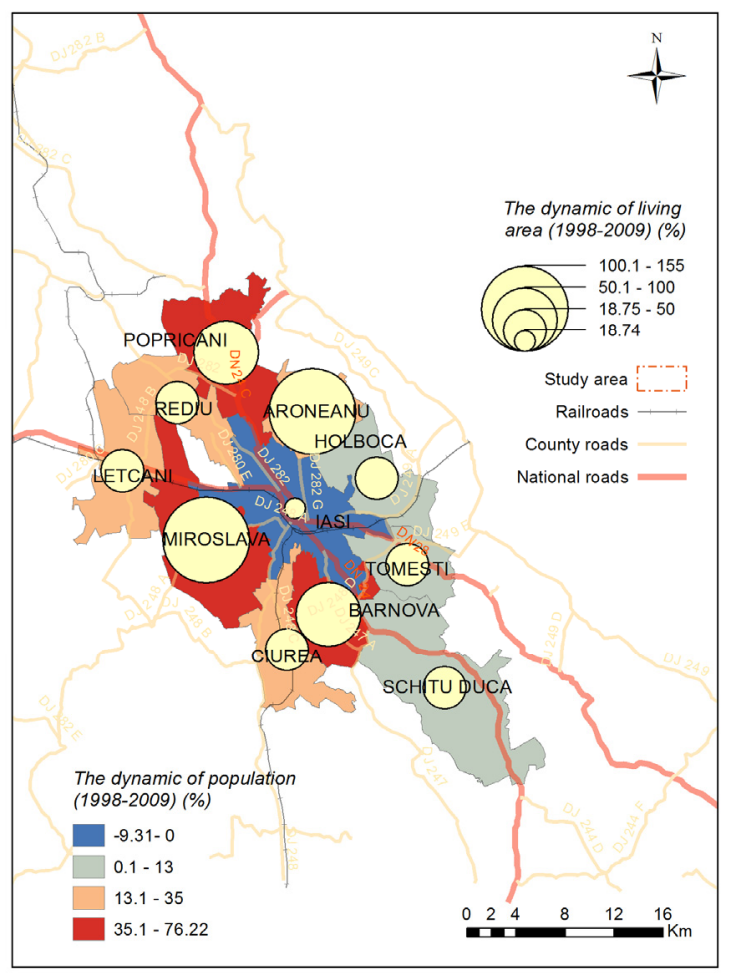

Figure 2: The relation between the dynamic of population and of the living area in the study area.

The evolution of the living area per person for the same period, represented in the chart below, confirms the fact that some of the most dynamic rural 
communes in terms of demographics (Aroneanu and Miroslava) offer the best living conditions from this point of view. However, there are also a few surprising results, especially the high rate for Tomesti and the city of Iasi, which might point to the fact that even if the dwelling construction is not very dynamic in relative numbers in these localities, the new dwellings are more spacious and they might therefore offer an indication of a higher standard of living of the owners.

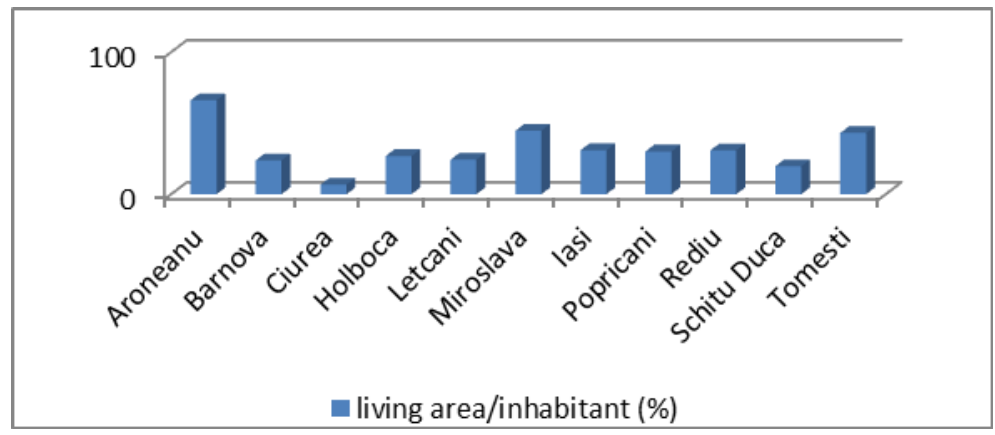

Figure 3: $\quad$ The dynamic of the living area per inhabitant (1998-2009).

A considerable increasing of the living area per inhabitant is one of the main features of urban sprawl and while it is an indication of higher comfort, it also brings up the matter of increasing distances between the urban functional areas and raises thus the problem of transport.

We have considered first the matter of the car ownership, as we believe it is highly relevant in the process of urban sprawl. The forth figure representing the dynamic of dwellings and car ownership reveals a correlation between the two indicators (Travisi et al. [2]). Thus, we can see that the highest rates of dwellings' dynamic are usually accompanied by a considerable growth of the car ownership rate. It is the case of Barnova (65\% for dwellings and $1695 \%$ for cars), Miroslava (72\% dwellings and $1293 \%$ for cars), Aroneanu (42\% dwellings and $861 \%$ cars), Popricani (30\% dwellings and $1116 \%$ cars) and Letcani $(26 \%$ dwellings and $1026 \%$ cars).

There are also a few exceptions, where a very high rate of cars ownership does not assure a similar behaviour of the dwellings' dynamic, like the case of Schitu Duca, commune that has a rate of $1300 \%$ for cars and the lowest rate of all for dwellings (14\%) and also of Holboca (802\% cars and 15\% dwellings). Even if the city has the greatest number of cars, the percentage increase for this time frame is much lower than those of the neighbouring communes, as concerning also the number of dwellings. It is a clear indication that the rhythm of development is higher in the rural areas. These are the effects of deconcentration inherent to urban sprawl (Nuissl and Rink [3]). On the other hand, the communes that were closely connected to the industrial areas and where we may even find housing blocks, like Tomesti and Holboca, seem to be less attractive for living, despite the fact that they have a better connectivity to the city services. 


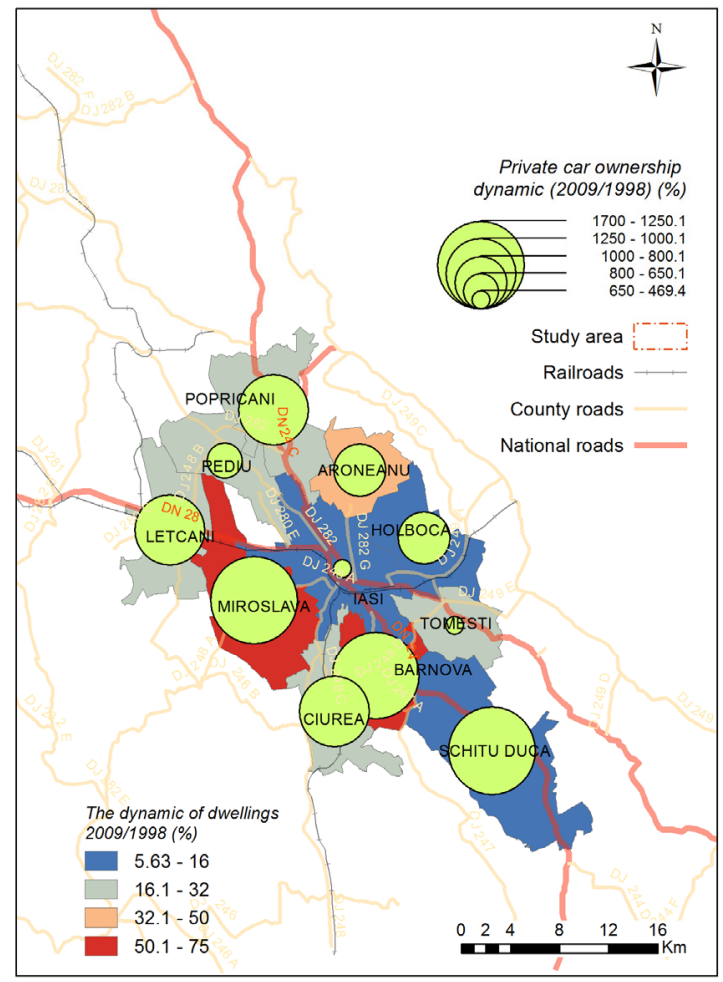

Figure 4: The relation between the dynamic of dwellings and of the car ownership.

There are strong indications that the evolution of car ownership has an influence on the demographic and real estate behaviour in the area of study. In order to have more prove, we have chosen to monitor the traffic towards and from the main exits of the city.

\section{Monitoring car flows in urban peripheries}

The traffic monitoring towards the periurban areas of Iasi municipality has been undertaken in the seven most important exits of the city (Letcani, Ciurea, Barnova, Tomesti, Popricani, Miroslava, Breazu) during three key time slots of the day: 7:00-9:00h, 12:00-14:00h, 15:30-18:00h corresponding to the two rush hour moments in the morning and afternoon, but also to the segment of an apparent traffic normality between 12:00-14:00. To replicate as correct as possible the dynamic of the road traffic, we have separated these segments in quarters of hour pointing out the key moments of the traffic. The measurements took place during three days of the week and the values presented in the following diagrams represent the sum of those three days for each time slot. 
We can easily notice that the most intense traffic is registered at the exit towards Letcani, being closely followed by the exit for Ciurea (these two exits dominate also the section of the inter-urban public transport) and those for Barnova and Tomesti. The following three exits (Breazu, Miroslava, and Popricani) show much lower values, their importance being, obviously, of smaller significance. The four dominant exits present different behaviours, even opposite, if we analyse the evolution of the traffic curve over the day. The traffic towards Letcani is marked by a clear dominance of the exits from the city in the time slot 7:00-9:00h, the rapport being opposite for the segment 15:30-18:00h. This behaviour can be explained by the deployment of the tertiary in the nearby area of Letcani (hypermarkets such as Metro, Dedeman, Praktiker, Era Shopping Park). This sector offers a substantial number of work places for the residents of the city of Iasi. The domination of entrance traffic in Iasi from Letcani area in the time slot 15:30-18:00h is less important due to a slight increase of the exits. This behaviour can be considered normal, if we take into account the fact that the area is heavily covered by diverse commercial areas.

The exits towards Barnova and Ciurea have a different traffic behaviour, with a high predominance of entrance traffic in Iasi during the time slot 7:00-9:00h, balanced by the high number of exits between 15:30-18:00h. These areas have more likely a residential function, without economic activities capable to offer a significant number of work places. Thus, these residents have become labour force for the city of Iasi. Though, it is necessary to make an important addition in order to differentiate these two areas that present, apparently an identical behaviour. Barnova area can be categorized as the establishment of high class residences, with a high land price and an even higher building price than other rural communes around the city of Iasi. The analysis of Iasi exit for Ciurea shows rather a higher number of buses in the time slot 7:00-9:00h and 15:3018:00h compared to the data from the same time slots for Barnova. These means of transport are meant to ensure a low budget access of the population to and from their work places and/or study.

An explanation regarding the dynamics of the traffic flow registered at the exit towards Barnova is highly necessary. Monday presents higher levels (10$15 \%$ ) of the car flow heading for Iasi in the time slot 7:00-9:00h and from the city between 15:30-18:00h compared to the other days of the week. This anomaly, although typical for all the observation points, is very clearly visible for Barnova exit and it is due to the administrative role of the Iasi municipality, which attracts the population from the rural areas of the county in order to solve their administrative or legal problems.

The exit towards Tomesti presents the most atypical behaviour of all four important exits of Iasi. In this case, there is almost a perfect balance between entrances and exits at all levels (time slots and days of the week). This balance is due to an equality report between the function of residential area, the number of available jobs in Tomesti and the importance of the exit for the communication with the south-east of the county. 


\section{Pacurari}

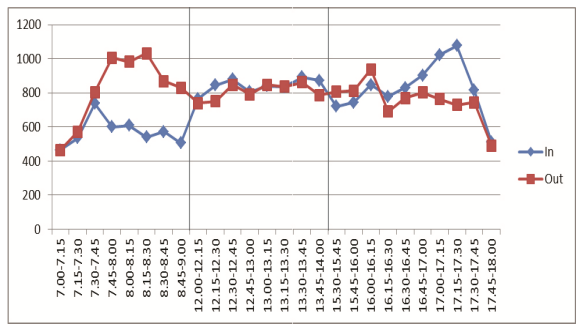

Miroslava

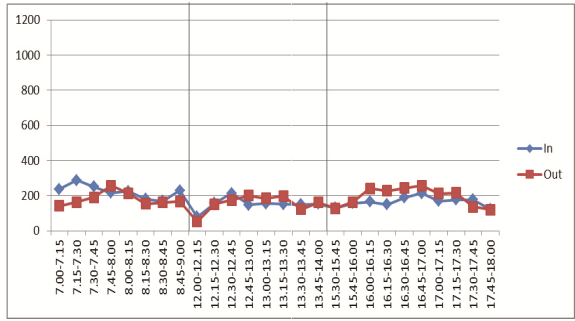

\section{Bucium}

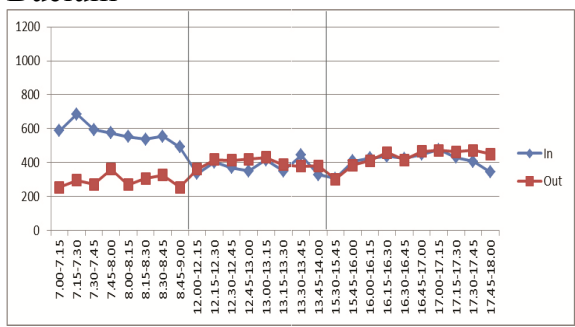

\section{Popricani}

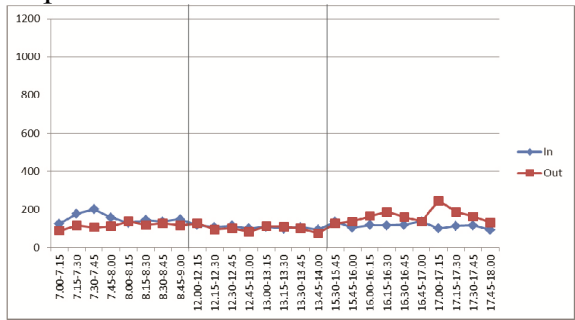

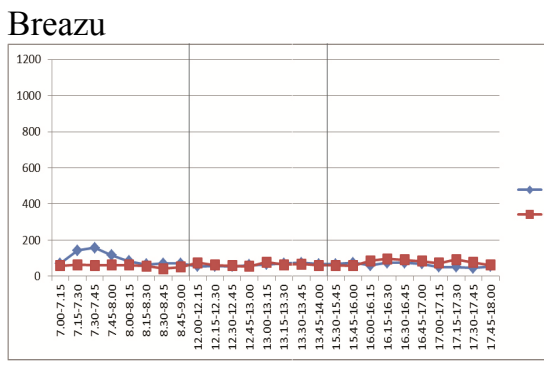

Ciurea
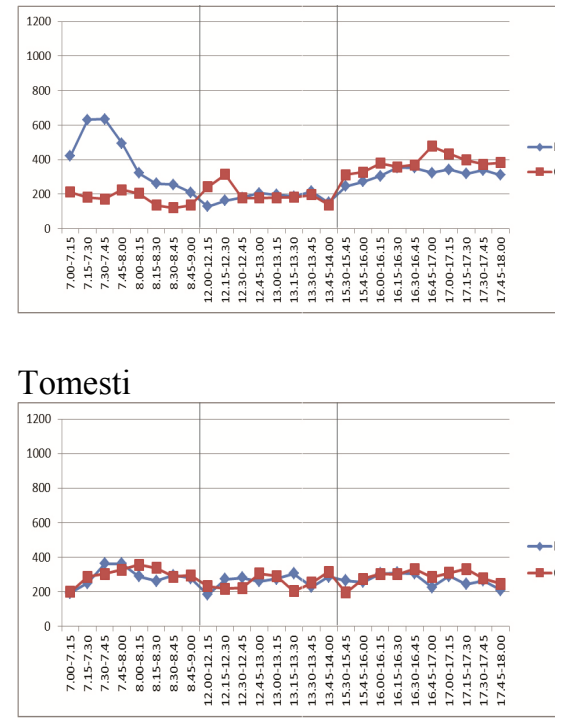

Figure 5: The preliminary results of traffic monitoring.

The only characteristic that applies to all exits, regardless of the values registered during the monitoring, is the existing balance between the entrance car flows and the exit ones between 12:00-14:00h, time during which there is a normal traffic activity. 


\section{The adverse impact of urban sprawl on land cover}

According to CLC, the territorial balance at the national scale for Romania between 2000 and 2006 emphasizes the consummation of natural area in favour of the artificial ones. However, at a micro-spatial level, data regarding the land cover for the municipality of Iasi and its periurban area clearly reveal a decrease of agricultural areas $(-1,2 \%)$, forests and semi natural areas $(-1 \%)$ and wetlands $(-24,2 \%)$, but also an increase of the artificial surfaces $(8,37 \%)$ and the water bodies $(8,16 \%)$. This is a typical phenomenon, especially for the areas with the highest dynamic of dwellings, population and living area (the case of rural communes of Barnova and Miroslava). The situation is similar for the municipality of Iasi: despite the fact that CLC data show an increase of the forest area (figure 6), those are actually areas where the forestation process was repeated and mostly unsuccessful.

In the municipality of Iasi, the dense urban fabric provides limited opportunities for new constructions. Under these circumstances, the built-up

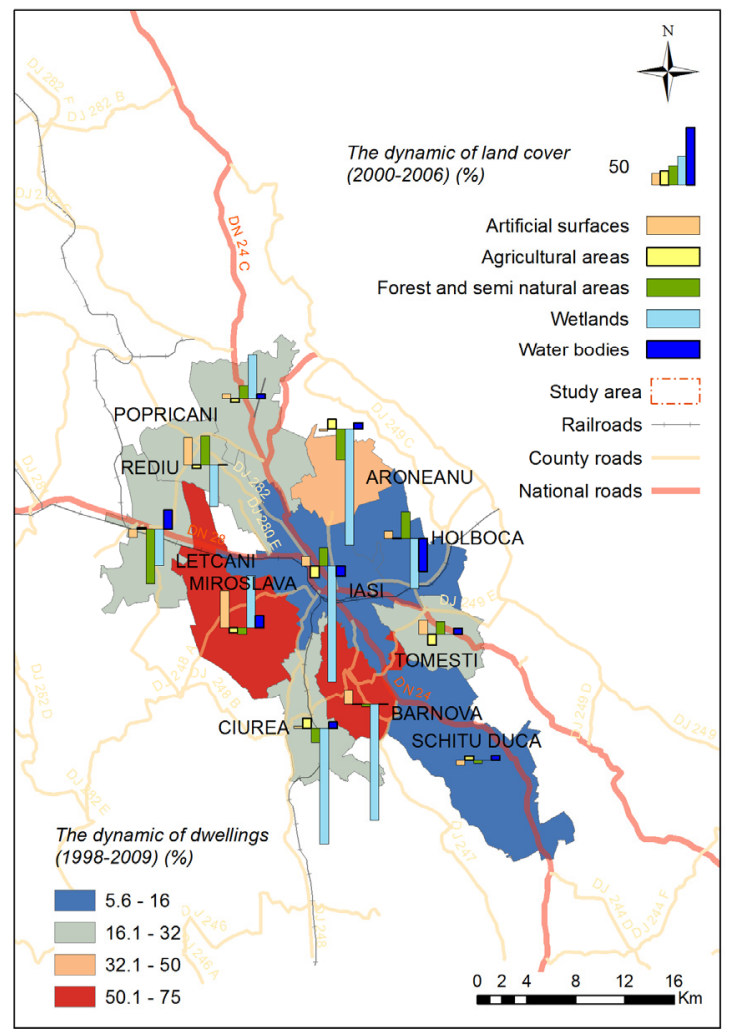

Figure 6: The relation between the dynamic of dwellings and the land cover. 
areas that are not covered with artificial surfaces are submitted to the pressure of real estate speculations. As a traditional wine centre, enjoying a true vine-fruit belt, the city had significant areas of vine. Because of the allotments issued after the Land Law 18/1991, which have found a favourable policy framework starting with 1998, these areas have been mostly sold and disbanded in favour of housing due to shortages of available land in the city and to the attractiveness of the locations (bellevue areas). Pre-accession funds before 2007 have reversed the trend of this indicator, convenient subsidies favouring the restoration of the vines almost to the same level as they were at the moment of the allotments (figure 7). The remainder of areas is however noticeable in the surfaces of land occupied mainly by the houses built on slopes that have a precarious geomorphological balance after the dismantling of the vineyards and after being loaded with buildings. Their location in the outskirts of the city has favoured the expansion of the urban area of Iasi towards the neighbouring areas, sparsely equipped with technical infrastructure, public utilities or other services.

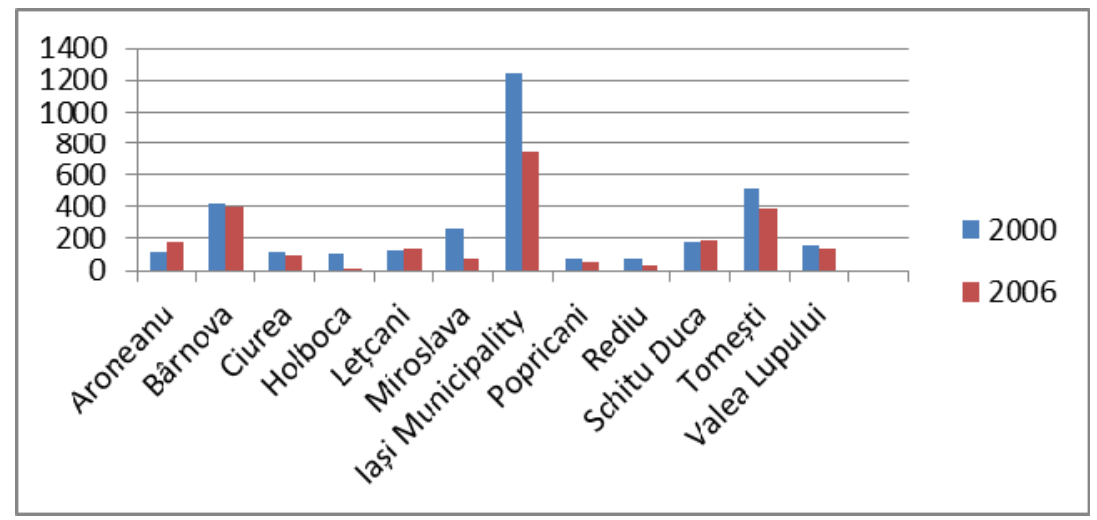

Figure 7: $\quad$ The dynamic of vineyards (-ha-).

This situation favours the increase of traffic, especially of the private cars: the owners generally have above-average incomes and use their personal car for daily trips, even when the improvement of public transport is obvious, as a result of the expansionist trend of the city. Although the increase in the number of vehicles is a result of the development of the economy and transport demand, it can lead to side effects like traffic congestion and air pollution caused by excessive use of vehicles (Wang et al. [4, p. 86]) with a negative impact on population.

\section{Conclusions}

According to the results of our short analysis, it is obvious that the urban expansion tends to be very dynamic towards the rural areas surrounding the municipality of Iasi. The main recipients of the residential areas seem to be the communes of Miroslava, Barnova, Aroneanu, Popricani and Letcani. Besides the 
increase of dwellings and population number, some of them benefit also from the existence of commercial and services areas, fact that has a great impact on the daily flows exchanged with the city. It also sets a certain functional specialization pattern: mainly residential for some of the communes (Aroneanu, Popricani, Ciurea) and mixed for others (Miroslava, Letcani, Tomesti).

We have also seen that the necessity to travel to and from the city for work and certain services has led to a spectacular increase of the number of cars, especially in the communes where public transport is less efficient. The connection between the urban sprawl and the transport system, either private or public, seems to be a strong one, but we can see that the influence of the cars is a decisive one (for instance, there is no transport line of the Local Public Transport Company towards the commune with the highest growth rate, Miroslava; instead, in this commune there is a significant increase of car ownership).

Due to the particularities of land cover in the most dynamic communes (especially to forests and water bodies), the form of the urban sprawl in the case of Iasi seems to resemble to what is known as leapfrog (Deal and Schunk [5]). This makes it even more difficult for the authorities to manage an infrastructure for city services that is currently highly insufficient in the communes, as well as in some of the new peripheral residential areas of the city, and they will not be able to cover the entire territory even after the completion of the projects planned by the Iasi Metropolitan Area for the following years.

\section{Acknowledgements}

This work was partially supported by the European Social Fund in Romania, under the responsibility of the Managing Authority for the Sectorial Operational Programme for Human Resources Development 2007-2013 [grant POSDRU/6/1.5/S/25, POSDRU/88/1.5/S/47646].

\section{References}

[1] Liu, S., Triantis, K. P., Sarangi, S., A framework for evaluating the dynamic impacts of a congestion pricing policy for a transportation socioeconomic system. Transportation Research, Part A 44, pp. 596-608, 2010.

[2] Travisi, C. M., Camagni, R., Nijkamp, P., Impacts of urban sprawl and commuting: a modelling study for Italy. Journal of Transport Geography, 18, pp. 382-392, 2010.

[3] Nuissl, H., Rink, D., The 'production' of urban sprawl in eastern Germany as a phenomenon of post-socialist transformation. Cities, 22 (2), pp. 123 $134,2005$.

[4] Wang, J., Lu, H., Peng, H., System Dynamics Model of Urban Transportation System and Its Application. Journal of Transportation Systems Engineering and Information Technology, 8 (3), pp. 83-89, 2008.

[5] Deal, B., Schunk, D., Spatial dynamic modelling and urban land use transformation: a simulation approach to assessing the costs of urban sprawl. Ecological Economics, 51, pp. 79- 95, 2004. 